\title{
Branched Methoxydiphenylamine-Substituted Carbazole Derivatives for Efficient Perovskite Solar Cells: Bigger Is Not Always Better
}

Povilas Luizys, "Jianxing Xia,, Maryte Daskeviciene, Kristina Kantminiene, Ernestas Kasparavicius, Hiroyuki Kanda, Yi Zhang, Vygintas Jankauskas, Kasparas Rakstys, Vytautas Getautis,* and Mohammad Khaja Nazeeruddin*

Cite This: Chem. Mater. 2021, 33, 7017-7027

Read Online

ABSTRACT: A set of novel branched molecules bearing a different number of 3,6-bis $\left(4,4^{\prime}\right.$-dimethoxydiphenylamino)carbazole-based $(\mathrm{Cz}$ OMeDPA) periphery arms linked together by aliphatic chains have been developed, and their performance has been tested in perovskite solar cells (PSCs). Electrical and photovoltaic properties have been evaluated with respect to the number of $\mathrm{Cz}-\mathrm{OMeDPA}$ moieties and the nature of the linking aliphatic chain. The isolated compounds possess sufficient thermal stability and are amorphous having high glass-transition temperatures $\left(>120{ }^{\circ} \mathrm{C}\right)$ minimizing the risk of direct layer crystallization. The highest hole-drift mobility of $\mu_{0}=3.1 \times 10^{-5} \mathrm{~cm}^{2} \mathrm{~V}^{-1} \mathrm{~s}^{-1}$ is comparable to that of the reference standard spiro-OMeTAD $\left(4.1 \times 10^{-5} \mathrm{~cm}^{2} \mathrm{~V}^{-1} \mathrm{~s}^{-1}\right)$ under identical conditions. Finally, PSCs employing two new HTMs (2CzOMeDPA and 3Cz-OMeDPA-OH) bearing two and three substituted

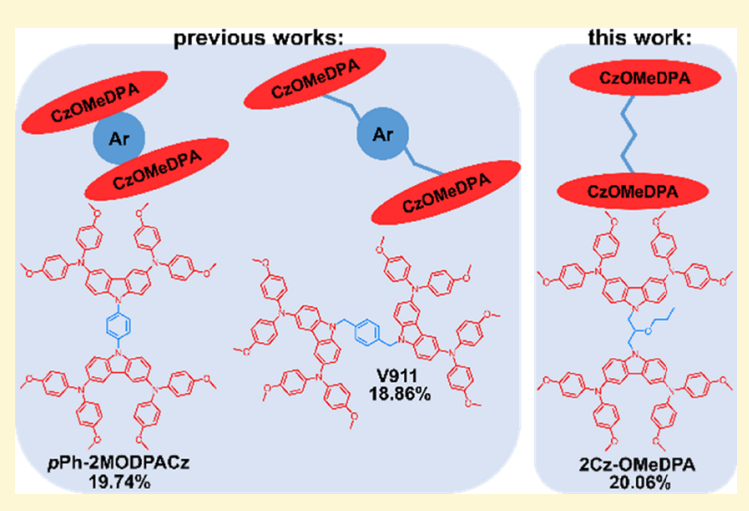
carbazole chromophores, linked by an aliphatic chain, show a performance of around $20 \%$, which is on par with devices using spiro$\mathrm{OMeTAD}$ and demonstrates slightly enhanced device stability.

\section{INTRODUCTION}

Over the recent years, organic-inorganic hybrid perovskite solar cells (PSCs) have been receiving marked worldwide attention owing to their low cost and facile fabrication. ${ }^{1}$ Since 2009, when Miyasaka and coworkers reported a 3.8\% power conversion efficiency (PCE) of PSCs, ${ }^{2}$ the performance of these photovoltaic devices has increased dramatically and currently, PCE exceeds $25 \%$. $^{3}$

A typical conventional PSC consists of a lead-halide perovskite layer sandwiched by an electron-selective layer and an organic hole-selective material, which is an important counterpart to produce high efficiency due to effective hole extraction/collection and electron blocking from the perovskite to the metal anode., ${ }^{4,5}$ The well-known spirobifluorene derivative $2,2^{\prime}, 7,7^{\prime}$-tetrakis-( $N, N$-di- $p$-methoxyphenylamine)9,9'-spirobifluorene (spiro-OMeTAD) is the most widely used hole-transporting material (HTM) in PSCs. As spiroOMeTAD is relatively expensive, ${ }^{6}$ the synthesis of novel lowcost and highly efficient HTMs is still a determinant challenge for future large-scale PSC production. Recently, HTMs representing various classes of organic compounds have been synthesized, as reviewed in numerous review articles. ${ }^{7-16}$

The low-cost $9 H$-carbazole as a starting material is interesting due to its excellent charge-transport properties and simple functionalization of the structure with a variety of different groups, which enable fine-tuning of the optical and electronic properties of target HTMs. ${ }^{17,18}$ Therefore, carbazole-based derivatives have been employed in organic lightemitting diodes $^{19,20}$ and dye-sensitized solar cells. ${ }^{21-23}$ In recent years, carbazole has also attracted much attention in PSCs. ${ }^{24-29}$

In this context, the 3,6-bis $\left(4,4^{\prime}\right.$-dimethoxydiphenylamino)carbazole moiety, whose facile synthesis requires just a few steps from commercially available and cheap starting reagents, has been widely explored. ${ }^{30-32}$ The majority of these studies consistently demonstrate that the number of carbazole-based periphery arms in $N$-aryl substituted carbazole molecules is of crucial importance for solar cell PCE. ${ }^{40}$ For example, hole mobility and conductivity of X51 are higher than those of X19, leading to better photovoltaic performance of the investigated devices $^{30}$ (Figure 1a). The results are congruous with the

Received: June 18, 2021

Revised: August 11, 2021

Published: August 19, 2021 


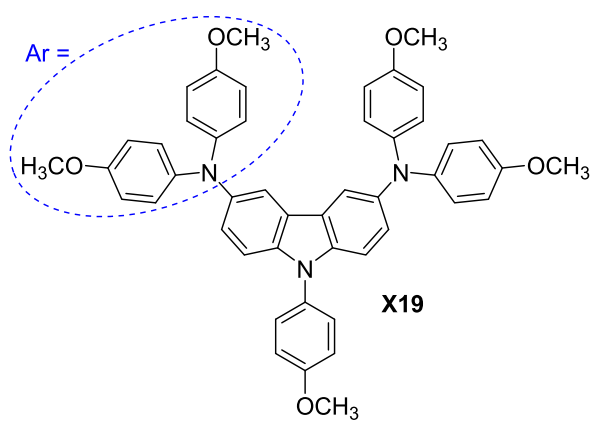

a)
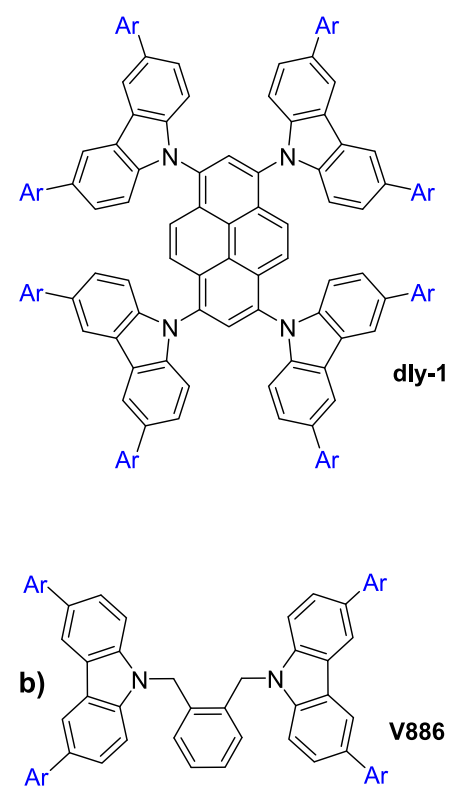
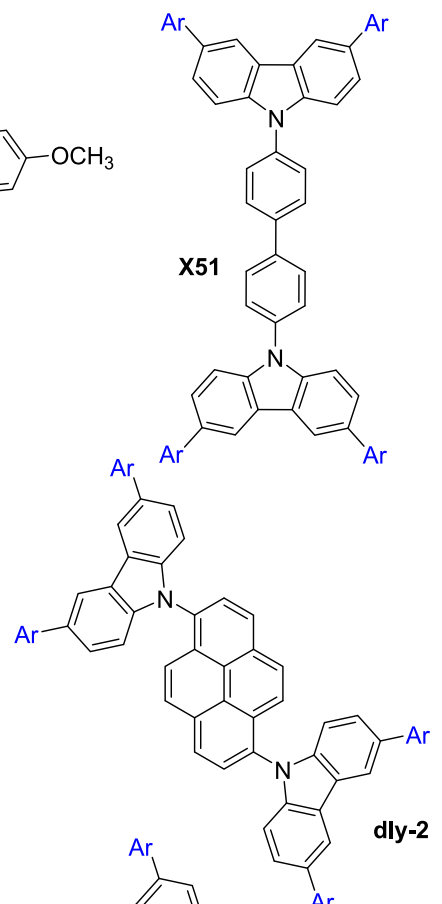

dly-2

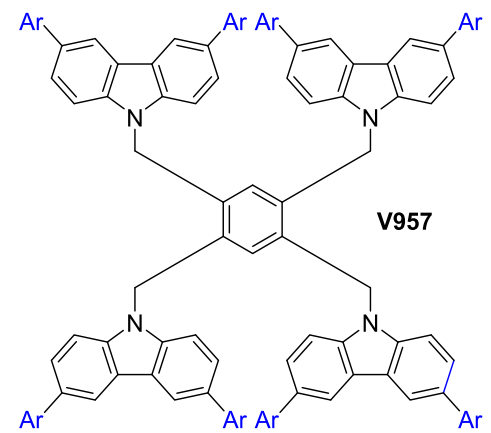

Figure 1. Chemical structures of the reported HTMs containing Cz-OMeDPA arms: (a) N-aryl substituted carbazole molecules and (b) partially nonconjugated carbazole derivatives.
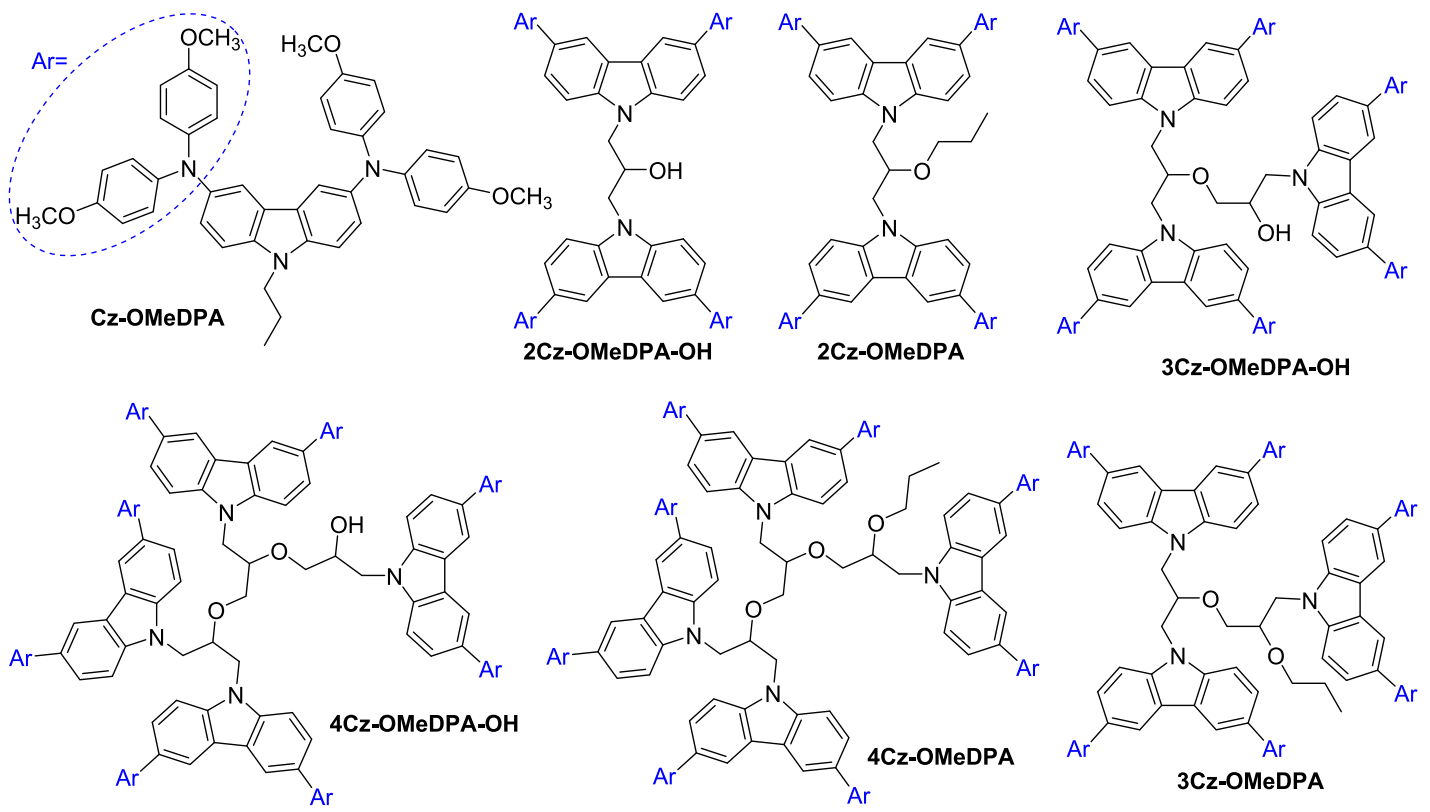

Figure 2. Chemical structures of the $N$-alkyl substituted carbazole HTMs containing OMeDPA arms reported herein.

expected influence of the larger conjugated system in the HTM X51. However, the PCE of PSCs, in which the tetraphenylethylene-based structure with four carbazole-based periphery arms (dly-1) is employed as HTM, is lower than that of the devices with the semiconductor bearing two carbazole-based periphery arms as HTM (dly-2). ${ }^{31}$ In their study of $\mathrm{N}$-aryl 


\section{Scheme 1. Divergent Synthesis Route to Cz-OMeDPA, 2Cz-OMeDPA, and 3Cz-OMeDPA}
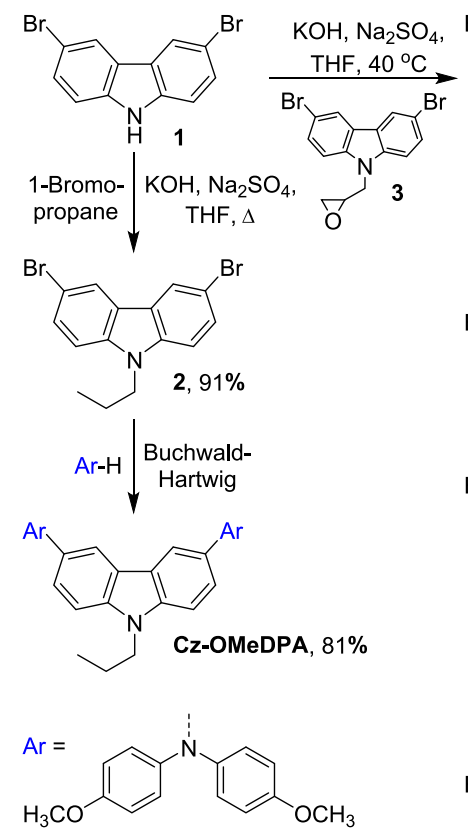
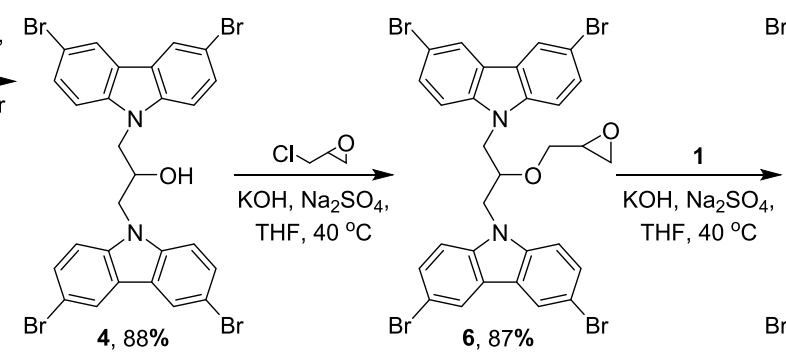

$4,88 \% \quad \mathrm{Br}$

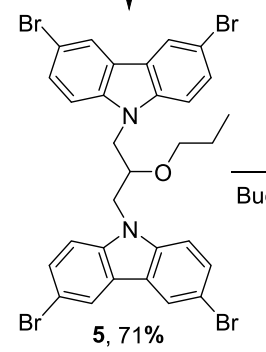

1-Bromopropane $\mathrm{KOH}, \mathrm{Na}_{2} \mathrm{SO}_{4}$, $\mathrm{THF}, \Delta$

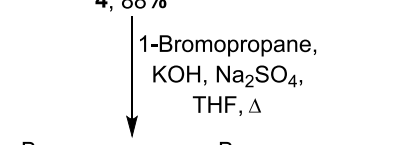

(2)
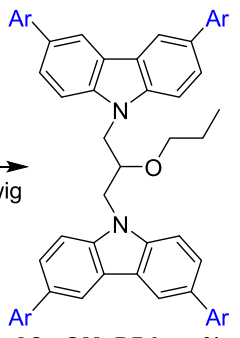

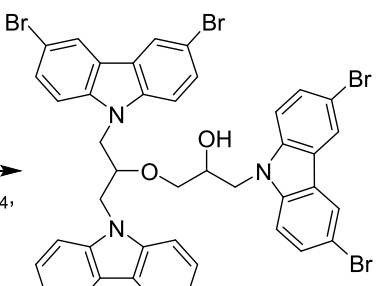

$\mathrm{Br}$ $\mathrm{Br} \quad 7,80 \%$
1. 1-Bromopropane, $\mathrm{KOH}$, $\mathrm{Na}_{2} \mathrm{SO}_{4}$, THF, $\Delta, 73 \%$ 2. Ar-H, Buchwald-Hartwig

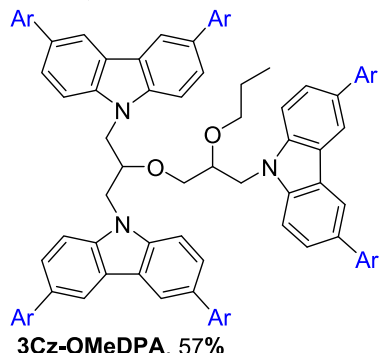

substituted carbazole derivatives, $\mathrm{Wu}$ and coworkers have demonstrated that the number of carbazole-based periphery arms significantly influences the physical properties of HTM and its application in PSCs. HTM bearing four arms (W4) has been shown to perform very well in PSCs, whereas HTM bearing just two arms (W3) was not even tested due to insufficient solubility ${ }^{32}$ (Figure 1a). Interestingly, a twin molecule, V886, bearing a partially nonconjugated 1,2bismethylbenzene core has demonstrated almost state-of-theart performance. ${ }^{33}$ In the consistent study of this type of compound, we have demonstrated that performance of such twin molecules can be improved by modifying carbazole-based periphery arms in the central benzene core. However, an increased number of branches in V1039 and V957 did not improve the performance ${ }^{34}$ (Figure $1 \mathrm{~b}$ ).

To the best of our knowledge, 3,6-bis $\left(4,4^{\prime}\right.$ dimethoxydiphenylamino) carbazole derivatives bearing photoconductive chromophores linked by aliphatic chains have not been employed in PSCs as HTMs. However, Benhattab et al. synthesized carbazole-based twin molecules linked by nonconjugated linear alkyl chains of different lengths and investigated the properties of these twin molecules in the solid-state DSSCs for the first time. They have demonstrated that conjugated linkers are not essential for designing twin molecules. 35

Alkyl chains are attracting attention as they usually improve solubility and, therefore, enhance the pore filling of the perovskite layer by HTM forming a strong and close attachment to the perovskite to enhance charge transfer. The HTM therefore is needed to have a low tendency to crystallize, easily forming a smooth layer at the interface to favor the charge transfer. In a majority of cases, the alkyl chains are the ones to significantly influence the stability of the amorphous state, which is of crucial importance in the formation of goodquality layers. $^{36}$

Considering the above-mentioned information, we report the synthesis of branched molecules bearing a different number of 3,6-bis $\left(4,4^{\prime}\right.$-dimethoxydiphenylamino) carbazole-based (Cz-
OMeDPA) periphery arms linked together by aliphatic chains (Figure 2) and investigation of their structure-property relationship. The photoelectrical and photovoltaic properties of the novel compounds in PSCs have been investigated with respect to the number of $\mathrm{Cz}-\mathrm{OMeDPA}$ moieties and the nature of the linking aliphatic chain.

\section{RESULTS AND DISCUSSION}

Synthesis. The target compounds bearing one $(\mathbf{C z}-$ OMeDPA), two (2Cz-OMeDPA), or three (3Cz-OMeDPA) substituted carbazole chromophores linked by an aliphatic chain were synthesized according to a divergent synthesis pathway as depicted in Scheme 1. The alkylation reaction of 3,6-dibromocarbazole (1) with 1-bromopropane in THF in the presence of anhydrous $\mathrm{Na}_{2} \mathrm{SO}_{4}$ and $\mathrm{KOH}$ at a reflux temperature of the reaction mixture afforded 3,6-dibromo-9propyl-9H-carbazole (2). The Buchwald-Hartwig crosscoupling reaction of intermediate 2 with bis(4methoxyphenyl)amine provided the model compound $\mathbf{C z}$ OMeDPA with an extended $\pi$-electron conjugated system. With the aim of increasing the number of $\pi$-electron conjugated system by increasing the number of chromophores in the molecule, the target compound 2Cz-OMeDPA containing two linked carbazolyl moieties was synthesized. The reaction of 3,6-dibromo-9-epoxypropylcarbazole (3) with 3,6-dibromocarbazole in the presence of anhydrous $\mathrm{Na}_{2} \mathrm{SO}_{4}$ and $\mathrm{KOH}$ afforded 1,3-bis(3,6-dibromo-9H-carbazol-9-yl)-2propanol (4). However, the attempts to carry out the Buchwald-Hartwig reaction of $\mathbf{4}$ with bis(4-methoxyphenyl)amine failed. It has been assumed that the hydroxyl group in the molecule passivates the catalyst. Therefore, the hydroxyl group was replaced by the propoxy group during the alkylation reaction of 4 with 1-bromopropane to give 1,3-bis(3,6dibromo-9H-carbazol-9-yl)-2-propoxypropane (5). The Buchwald-Hartwig reaction of intermediate 5 with bis(4methoxyphenyl)amine afforded the target twin molecule 2Cz-OMeDPA. 
Scheme 2. Convergent Synthesis Route to 2Cz-OMeDPA-OH, 3Cz-OMeDPA-OH, 4Cz-OMeDPA, and 4Cz-OMeDPA-OH
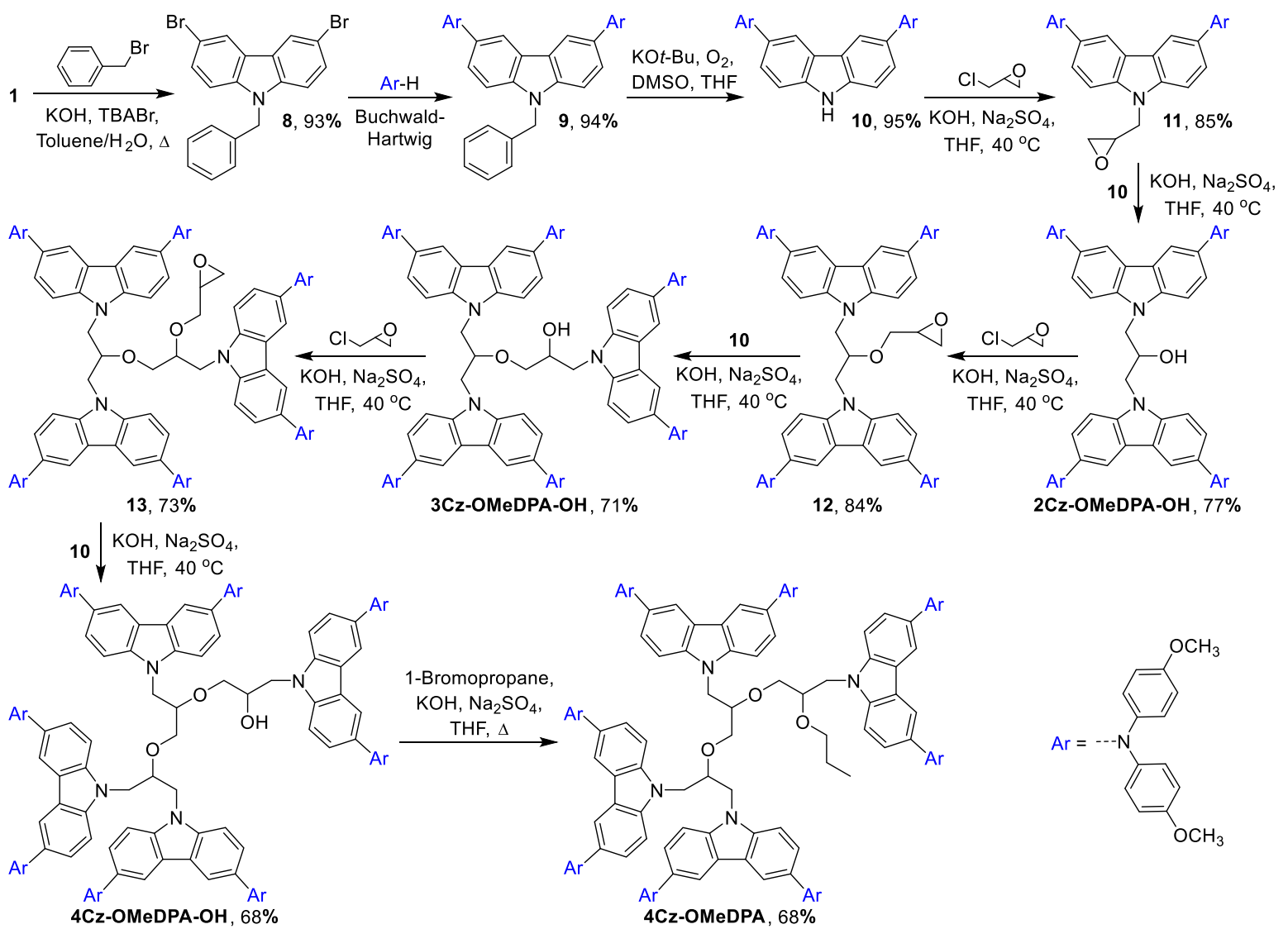

\section{$\operatorname{Ar}$}

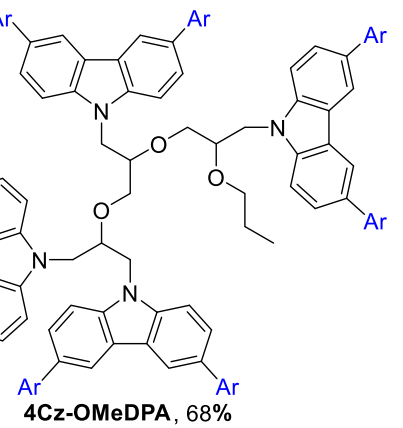

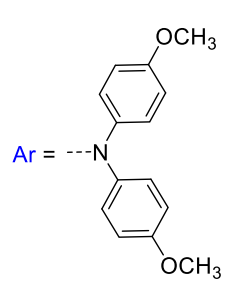

As the next step toward an increased number of photoconductive moieties, the derivative 3Cz-OMeDPA bearing three carbazolyl chromophore molecules was synthesized. First, dimer 4 was transformed into its glycidyl ether $6^{37}$ via the reaction of 4 with epichlorohydrin to afford 1,3-bis(3,6dibromo-9H-carbazol-9-yl)-2-(2,3-epoxy)propoxypropane (6). Then, the nucleophilic oxirane ring opening reaction of 6 with 3,6-dibromocarbazole in THF in the presence of anhydrous $\mathrm{Na}_{2} \mathrm{SO}_{4}$ and $\mathrm{KOH}$ provided trimer 7 . Since the BuchwaldHartwig reaction does not occur in the presence of the hydroxyl group in the molecule, the alkylation reaction of 7 with 1-bromopropane was carried out to replace the hydroxyl group with the propoxy one in the intermediate compound, which was subsequently treated with bis(4-methoxyphenyl)amine under the conditions of the Buchwald-Hartwig reaction to obtain the target compound 3Cz-OMeDPA.

The attempts to synthesize a derivative bearing four substituted carbazole chromophores linked by an aliphatic chain via the divergent synthesis pathway did not yield the target compound. Therefore, this HTM was synthesized by the convergent synthesis route (Scheme 2). First, the intermediate compound 9-benzyl-3,6-dibromo-9H-carbazole (8) with the blocked $\mathrm{N}-\mathrm{H}$ group was synthesized in the reaction of 3,6dibromocarbazole (1) with benzyl bromide at reflux temperature of the toluene-water reaction mixture in the presence of $\mathrm{KOH}$ and tetrabutylammonium bromide as interphase catalyst. Next, the Buchwald-Hartwig reaction of $\mathbf{8}$ with bis(4methoxyphenyl)amine provided 9-benzyl-3,6-bis $\left(4,4^{\prime}\right.$-dimethoxydiphenylamino)-9H-carbazole (9), which was dissolved in dimethyl sulfoxide and treated with a $1 \mathrm{M}$ solution of potassium tert-butoxide in THF with the atmospheric oxygen participating in the reaction to give the unblocked 3,6-bis $\left(4,4^{\prime}\right.$ dimethoxydiphenylamino)-9H-carbazole (10). Compound 10 was converted into its oxirane derivative $\mathbf{1 1}$ in the reaction with epichlorohydrin. The next synthesis steps provided dimer 2Cz-OMeDPA-OH bearing the $\mathrm{OH}$ group in the linking aliphatic chain and its glycidyl ether 12 according to the synthesis procedure depicted for compound $\mathbf{6}$ in Scheme 1. Afterward, the reaction of glycidyl ether $\mathbf{1 2}$ with the precursor 10 afforded trimer $3 \mathrm{Cz}-\mathrm{OMeDPA}-\mathrm{OH}$ bearing the $\mathrm{OH}$ group in the aliphatic linker, which was not synthesized via a divergent synthesis route (Scheme 1). Treatment of the former compound with epichlorohydrin provided oxirane derivative 13, which upon subsequent reaction with precursor 10 afforded the target tetramer 4Cz-OMeDPA-OH, in which four substituted carbazole chromophores are linked by the aliphatic moiety bearing the $\mathrm{OH}$ group. The target compound 4Cz-OMeDPA was synthesized by alkylating the hydroxyl group in 4Cz-OMeDPA-OH with 1-bromopropane.

All HTMs bearing photoconductive chromophores in their molecules were purified by column chromatography followed by precipitation. Isolated by such a procedure, target products Cz-OMeDPA, 2Cz-OMeDPA, 2Cz-OMeDPA-OH, 3CzOMeDPA, 3Cz-OMeDPA-OH, 4Cz-OMeDPA, and $4 \mathrm{Cz}-$ OMeDPA-OH are amorphous compounds and all attempts to crystallize them failed. It can be assumed that the obtained high morphological stability of the synthesized compounds may be explained by the flexibility of the branched aliphatic binding chains between photoconductive chromophores. In addition, the existence of several diasteroisomers of $3 \mathbf{C z}$ OMeDPA, 3Cz-OMeDPA-OH, 4Cz-OMeDPA, and 4CzOMeDPA-OH, which have several chiral carbon atoms, is 

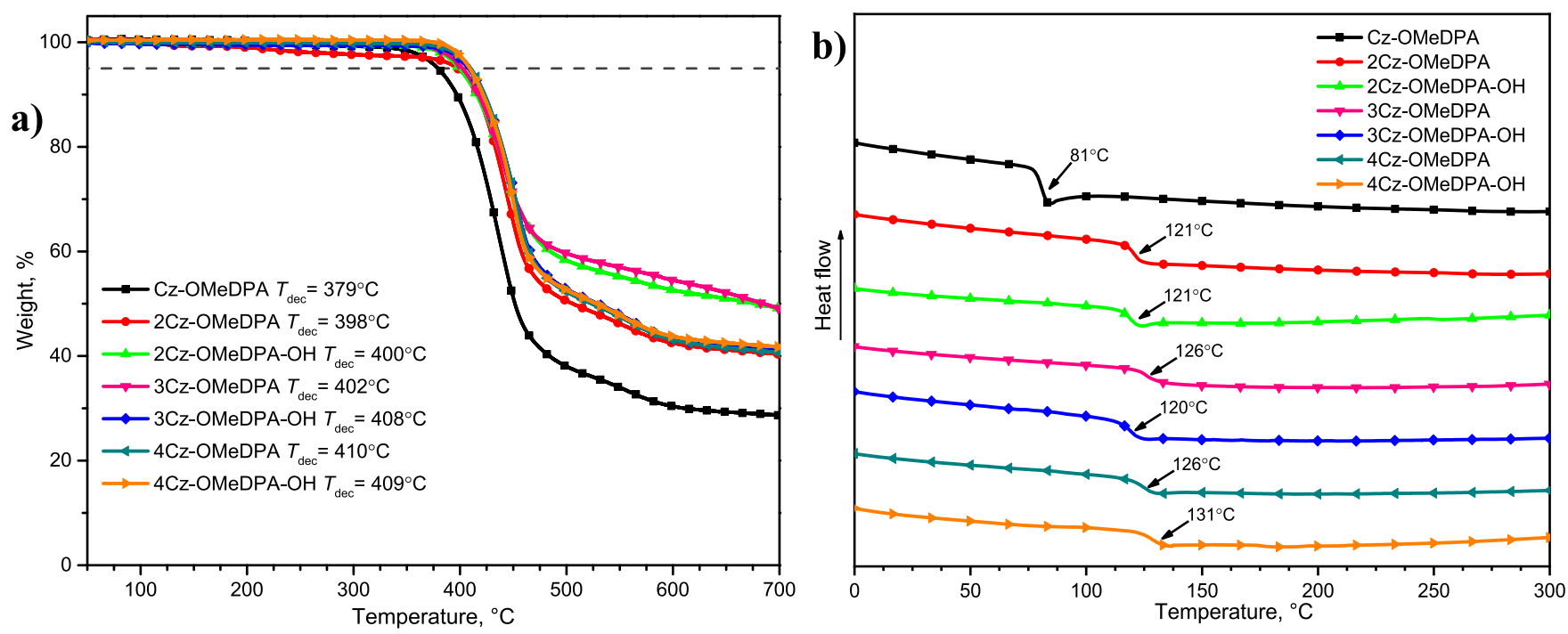

Figure 3. (a) TGA heating curves of the HTMs (heating rate of $10{ }^{\circ} \mathrm{C} / \mathrm{min}$ and $\mathrm{N}_{2}$ atmosphere) and (b) DSC curves of the second run (heating rate of $10{ }^{\circ} \mathrm{C} / \mathrm{min}$ and $\mathrm{N}_{2}$ atmosphere).

Table 1. Thermal, Optical, and Photophysical Properties of the HTMs

\begin{tabular}{lccccccccc}
\multicolumn{1}{c}{$\mathrm{ID}$} & $T_{\mathrm{g}}\left({ }^{\circ} \mathrm{C}\right)^{a}$ & $T_{\mathrm{dec}}\left({ }^{\circ} \mathrm{C}\right)^{a}$ & $\lambda_{\mathrm{abs}}(\mathrm{nm})^{b}$ & $\lambda_{\mathrm{PL}}(\mathrm{nm})^{b}$ & $\Phi_{\mathrm{PL}}(\%)$ & $I_{\mathrm{P}}(\mathrm{eV})^{c}$ & $E_{\mathrm{g}}(\mathrm{eV})^{d}$ & $E_{\mathrm{ea}}(\mathrm{eV})^{e}$ & $\mu_{0}\left(\mathrm{~cm}^{2} \mathrm{~V}^{-1} \mathrm{~s}^{-1}\right)^{f}$ \\
\hline Cz-OMeDPA & 81 & 379 & 305,372 & 448 & 23 & 4.99 & 2.92 & 2.07 & $2.2 \times 10^{-9}$ \\
2Cz-OMeDPA & 121 & 398 & 303,372 & 449 & 18 & 5.16 & 2.97 & 2.19 & $3.2 \times 10^{-6}$ \\
3Cz-OMeDPA & 126 & 402 & 303,372 & 449 & 18 & 5.08 & 2.92 & 2.16 & $2.4 \times 10^{-6}$ \\
4Cz-OMeDPA & 126 & 410 & 302,373 & 452 & 22 & 5.17 & 2.88 & 2.29 & $1.2 \times 10^{-6}$ \\
2Cz-OMeDPA-OH & 121 & 400 & 303,372 & 449 & 18 & 5.12 & 2.94 & 2.18 & $3.1 \times 10^{-5}$ \\
3Cz-OMeDPA-OH & 120 & 408 & 303,373 & 450 & 17 & 5.16 & 2.91 & 2.25 & $6.9 \times 10^{-6}$ \\
4Cz-OMeDPA-OH & 131 & 409 & 303,373 & 452 & 19 & 5.18 & 2.82 & 2.36 & $4.0 \times 10^{-6}$
\end{tabular}

${ }^{a}$ Glass-transition $\left(T_{\mathrm{g}}\right)$ and decomposition $\left(T_{\mathrm{dec}}\right)$ temperatures determined from DSC and TGA, respectively $\left(10{ }^{\circ} \mathrm{C} / \mathrm{min}\right.$ and $\mathrm{N}_{2}$ atmosphere). ${ }^{b} \mathrm{UV}$-vis and PL spectra were measured in THF solutions $\left(10^{-4} \mathrm{M}\right) .{ }^{c}$ Ionization energies of the films measured using PESA. ${ }^{d} E_{\mathrm{g}}$ estimated from

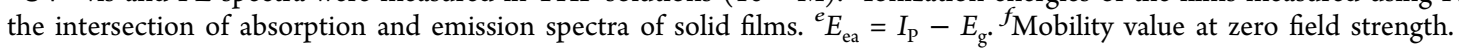

attributed to the stability of the amorphous state of these HTMs. The synthesized HTMs containing a different number of $\mathrm{Cz}$-OMeDPA arms have a well-defined structure, and they show good room-temperature solubility in a variety of organic solvents, i.e., acetone, toluene, chlorobenzene, MEK, and THF. The structures of the HTMs have been confirmed by ${ }^{1} \mathrm{H}$ NMR, ${ }^{13} \mathrm{C}$ NMR, IR spectroscopy, mass spectrometry, and elemental analysis.

Thermal Properties. The thermal behavior of the HTMs was evaluated by thermogravimetric analysis (TGA) and differential scanning calorimetry (DSC) measurements. The data are provided in Figure 3, and the summarized characteristics are listed in Table 1. As seen from the TGA results, all compounds are thermally stable up to $\sim 400{ }^{\circ} \mathrm{C}$, which is somewhat a lower temperature than that of spiro-OMeTAD $\left(T_{\text {dec }}=449{ }^{\circ} \mathrm{C}\right) .{ }^{38}$ The lowest $5 \%$ weight loss temperature $\left(T_{\text {dec }}\right)$ of $379{ }^{\circ} \mathrm{C}$ has been recorded for Cz-OMeDPA bearing one substituted carbazole fragment; however, it is still high enough, indicating sufficient thermal stability needed in PSCs. The highest $T_{\mathrm{dec}}$ of $410{ }^{\circ} \mathrm{C}$ has been determined for $\mathbf{4 C z}$ OMeDPA bearing four substituted carbazole chromophores linked by the branched aliphatic chain. Overall, just small variations in $T_{\mathrm{dec}}$ values have been observed in the set of the synthesized compounds with different numbers of $\mathrm{Cz}$ OMeDPA arms. However, a slight increase in $T_{\text {dec }}$ values can be noticed with the increasing number of photoconductive $\mathrm{Cz}$ OMeDPA arms in the synthesized HTMs. This tendency can, presumably, be explained by the higher molecular mass resulting in stronger intermolecular interactions. The same pattern has been observed for the compounds bearing the hydroxyl group in the branched aliphatic chain. Their $T_{\mathrm{dec}}$ values are slightly higher than those of the respective HTMs without hydroxyl groups. These results indicate the influence of the intermolecular hydrogen bonds.

DSC analysis has shown that all investigated compounds exist only in an amorphous state since no endothermic melting peaks were detected during both heating cycles (Figures S1S7). From the data in Figure $3 \mathrm{~b}$ and Table 1 , it can be found that the molecules bearing a different number of $\mathrm{Cz}-\mathrm{OMeDPA}$ moieties show just insignificant variations in $T_{g}$, i.e., $121-131$ ${ }^{\circ} \mathrm{C}$. The only notable exception is $T_{\mathrm{g}}$ of the compound $\mathbf{C z}-$ OMeDPA bearing just one substituted carbazole chromophore. Its $T_{\mathrm{g}}$ is much lower $\left(T_{\mathrm{g}}=81{ }^{\circ} \mathrm{C}\right)$ than those of the compounds bearing a greater number of carbazole fragments. With an increase in the number of substituted carbazole chromophores, the $T_{\mathrm{g}}$ values for 3Cz-OMeDPA, 4CzOMeDPA, and 4Cz-OMeDPA-OH are also increased, leading to a stabilized amorphous state compared with spiro$\mathrm{OMeTAD}\left(124{ }^{\circ} \mathrm{C}\right)$. In general, it is advantageous to use fully amorphous compounds as there is no risk of direct film crystallization in photovoltaic devices. ${ }^{38}$

Optical Properties. The optical properties were evaluated by UV-vis absorption and photoluminescence spectroscopy in dilute THF solutions and thin films on a glass substrate. UV- 


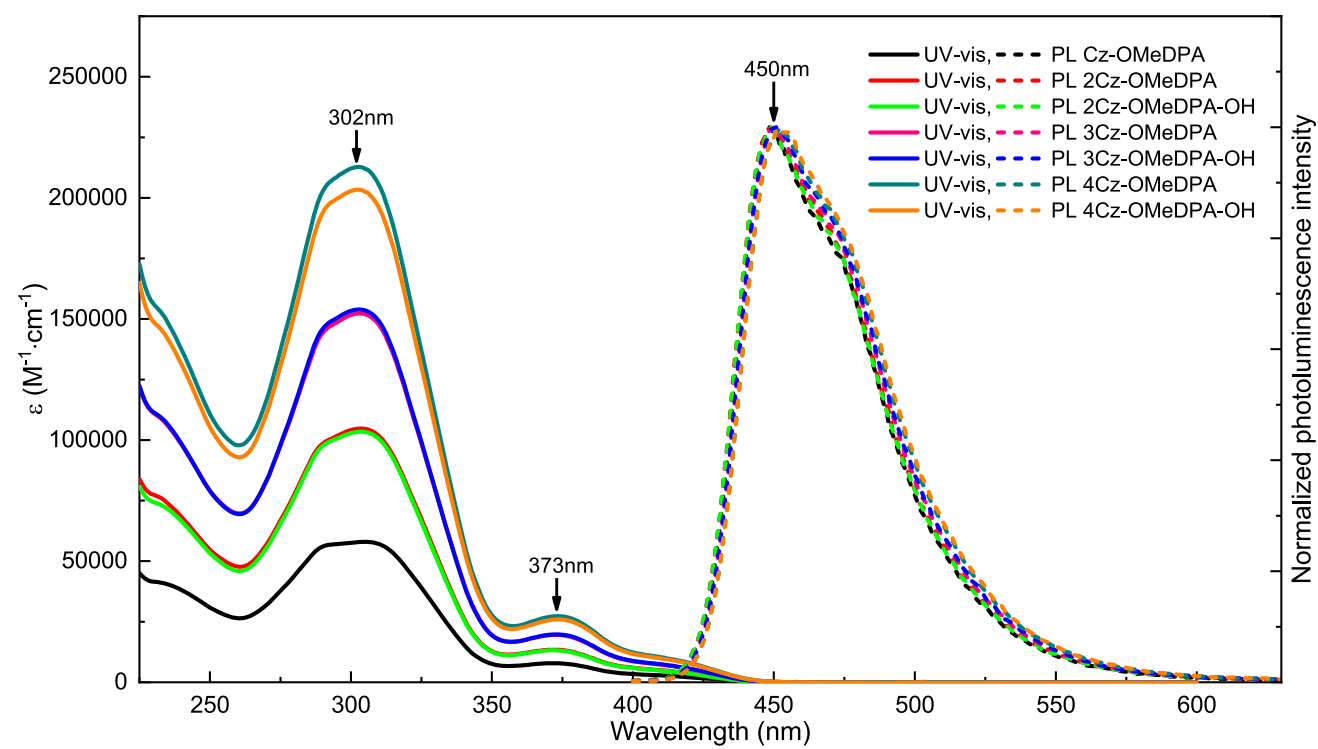

Figure 4. UV-vis absorption (solid line) and photoluminescence (dashed line) spectra of the investigated HTMs in THF solution (10 ${ }^{-4} \mathrm{M}$ ).

vis spectra of the synthesized compounds in solution are similar, as strong $\pi-\pi^{*}$ absorptivity is observed at $270-350$ $\mathrm{nm}$, and weaker energy absorption, which can be assigned to $n-\pi^{*}$ bands, is present at $\sim 373 \mathrm{~nm}$ (Figure 4 ). The different number of carbazole fragments in the molecules does not influence conjugation; just the hyperchromic effect is noted in the series starting from $\mathrm{Cz}-\mathrm{OMeDPA}$, through $2 \mathrm{Cz}$-OMeDPA and $\mathbf{3 C z}-\mathrm{OMeDPA}$, to $4 \mathrm{Cz}-\mathrm{OMeDPA}$. A similar trend was observed for the compounds 2Cz-OMeDPA-OH, $3 \mathrm{Cz}$ OMeDPA-OH, and 4Cz-OMeDPA-OH. Thus, absorptivity is directly proportional to the number of $\mathrm{Cz}-\mathrm{OMeDPA}$ moieties in the synthesized compounds. This relationship has been definitely proven once again by the structures of the synthesized HTM molecules. Changes in the branched aliphatic chains linking photoconductive chromophores do not influence the absorption spectra of the target compounds. The same pattern applies to the characteristics of the materials investigated in the thin films. Significant changes in the UVvis spectra have not been observed in the case of the films on the glass substrate (Figure S8). All investigated HTMs emitted light with a maximum at around $450 \mathrm{~nm}$ and a photoluminescence quantum yield $\left(\Phi_{\mathrm{PL}}\right)$ of $\sim 20 \%$ in THF solutions estimated using the integrated sphere method. ${ }^{41}$ In addition, a relatively large Stokes shift of $\sim 80 \mathrm{~nm}$ was observed for the synthesized compounds, which suggests significant changes in the geometry of the photoconductors upon excitation. We next calculated the optical gaps $\left(E_{\mathrm{g}}=2.9 \mathrm{eV}\right)$ from the intersection of UV-vis and PL spectra on glass substrates.

Photoelectrical Properties. To better understand the HOMO-LUMO level alignment of the synthesized HTMs in PSCs, the solid-state ionization potential $\left(I_{\mathrm{p}}\right)$ of their thin films was recorded by photoelectron emission spectroscopy in air (PESA), as shown in Figure 5. As it has been expected, among the molecules bearing the same chromophores linked together by aliphatic chains, only insignificant variations were detected, with the lowest value of $4.99 \mathrm{eV}$ measured for Cz-OMeDPA and the highest one of $5.18 \mathrm{eV}$ recorded for 4Cz-OMeDPAOH. In all cases, the $I_{\mathrm{p}}$ values are similar to that of spiroOMeTAD $(5.00 \mathrm{eV})$, which optimally offsets with the perovskite valence band energy $(\sim 5.5 \mathrm{eV})$; therefore, effective

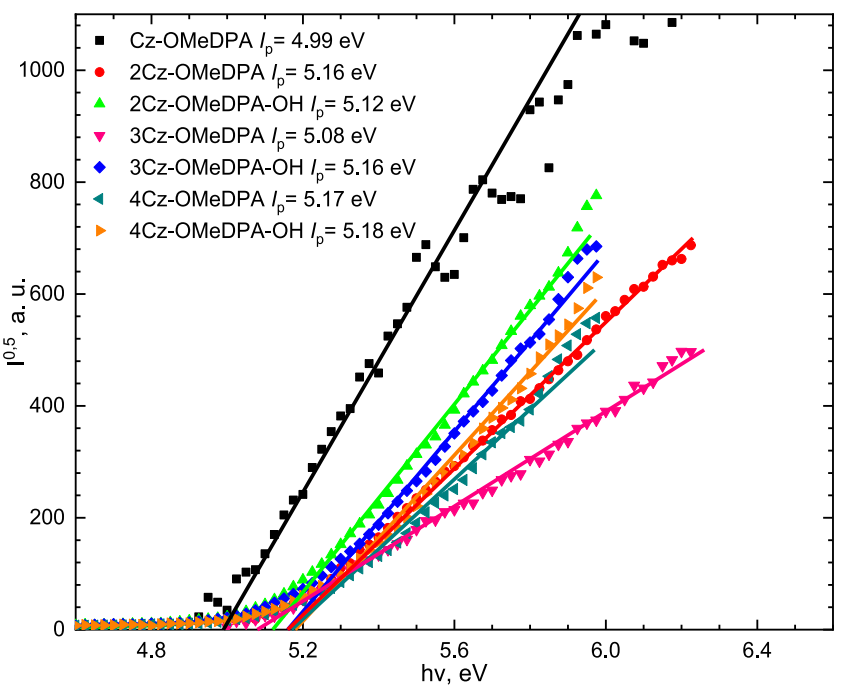

Figure 5. Photoemission in air spectra of HTMs.

hole transport from the photoactive perovskite to the electrode should be fulfilled.

Furthermore, the charge mobility of the synthesized HTMs was recorded using the xerographic time of flight (XTOF) technique for solution-processed films (for more details, see the Methods section) measuring hole-drift mobility on electric field strength dependency. The results obtained are shown in Figure 6. As shown in Table 1, in the series of the branched derivatives, the zero-field hole-drift mobility $\left(\mu_{0}\right)$ of $3.1 \times 10^{-5}$ $\mathrm{cm}^{2} \mathrm{~V}^{-1} \mathrm{~s}^{-1}$ for 2Cz-OMeDPA-OH is the highest, while that of the analogue with alkylated hydroxyl group 2Cz-OMeDPA is an order of magnitude lower $\left(3.2 \times 10^{-6} \mathrm{~cm}^{2} \mathrm{~V}^{-1} \mathrm{~s}^{-1}\right)$. Interestingly, a larger number of photoconductive chromophores have a negative influence on the hole-drift mobility of the synthesized HTMs. The hole-drift mobility of $3 \mathbf{C z}$ OMeDPA-OH with three Cz-OMeDPA moieties is somewhat lower than that of $2 \mathrm{Cz}-\mathrm{OMeDPA}-\mathrm{OH}$, while the value for HTM with four Cz-OMeDPA moieties (4Cz-OMeDPA-OH) was even lower at weak electric fields. The same pattern has been noticed among the HTMs with alkylated hydroxyl groups 


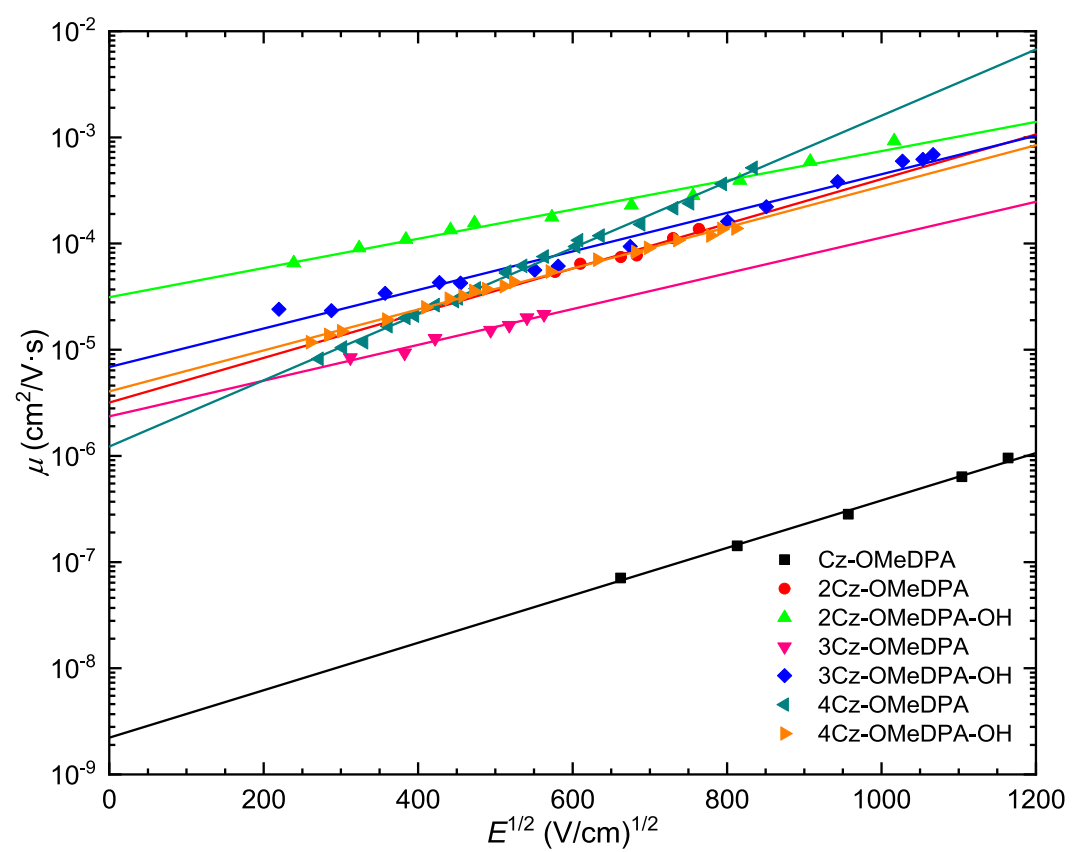

Figure 6. Electric field dependencies of the hole-drift mobility $(\mu)$ in charge transport layers of investigated HTMs.

2Cz-OMeDPA, 3Cz-OMeDPA, and 4Cz-OMeDPA. It is important to note that the hole-drift mobility value of $\mathbf{C z}$ OMeDPA is much lower $\left(2.2 \times 10^{-9} \mathrm{~cm}^{2} \mathrm{~V}^{-1} \mathrm{~s}^{-1}\right)$, showing that, in the present case, the nonbranched molecular structure is disadvantageous for the efficient hole transport.

The observed drop in charge mobility may be explained by the less ordered packing of the more branched molecules with a larger number of side groups since charges are hopping between molecules spaced further apart. Usually, the mobility in the molecular solids is calculated according to the Borsenberger, Pautmeier, and Bässler formula ${ }^{39}$

$$
\mu(E, T)=\mu_{0}{ }^{\prime} \exp \left[-\left(\frac{2 \sigma}{3 k T}\right)^{2}\right] \exp \left\{C\left[\left(\frac{\sigma}{k T}\right)^{2}-\Sigma^{2}\right] E^{1 / 2}\right\}
$$

Here, $\mu$ is the hole-drift mobility; $\mu_{0}{ }^{\prime}$ is the mobility prefactor; $\sigma$ is the energy width of the hopping site manifold, which is a measure of the energetic disorder; $\Sigma$ is the degree of positional disorder; $C$ is the empirical constant of $2.9 \times 10^{-4}$ $\left(\mathrm{cm} \mathrm{V}^{-1}\right)^{0.5} ; E$ is the electric field; and $k T$ has its usual meaning. As seen from formula 1 , the zero-electric field mobility $\mu(0, T)$ is determined mainly by the energetic disorder $\sigma$; therefore, we may assume that energetic disorder is lower in the case of less-branched HTMs bearing two or three $\mathrm{Cz}-\mathrm{OMeDPA}$ moieties as compared to the analogous compounds with four branches having the highest steric disorder. Finally, the hole mobility of $2 \mathrm{Cz}-\mathrm{OMeDPA}-\mathrm{OH}$ is equivalent to that of the reference standard spiro-OMeTAD $\left(4.1 \times 10^{-5} \mathrm{~cm}^{2} \mathrm{~V}^{-1} \mathrm{~s}^{-1}\right) .^{38}$

Photovoltaic Properties. The $n-i-p$ PSCs with the architecture $\mathrm{FTO} / \mathrm{C}-\mathrm{TiO}_{2} / \mathrm{SnO}_{2} / \mathrm{PCBM} /$ perovskite/HTM/ $\mathrm{Au}$ were fabricated, as shown in Figure $7 \mathrm{a}$ (the details are given in the Methods section). The $\mathrm{FAMAPbI}_{3}$ dominated the perovskite composition, and the HTM layers were doped. The thickness of the corresponding layers was determined by crosssectional scanning electron microscopy (SEM). The device was made by layering $700 \mathrm{~nm}$ perovskite atop a thin $\mathrm{SnO}_{2}$ nanoparticle layer, which was deposited on FTO glass coated with compact $\mathrm{TiO}_{2}$. The device was completed by $70 \mathrm{~nm}$ thick HTL and $70 \mathrm{~nm}$ gold as back contacts.

The current-voltage $(J-V)$ traces of the record devices of each HTM are provided in Figure $7 b$, and their PV parameters are summarized in Table 2; also, the statistics of PCE are presented in Figure S11. The PCE values of the most efficient devices containing 2Cz-OMeDPA, 3Cz-OMeDPA-OH, and spiro-OMeTAD were very similar, i.e., $20.06 \%, 19.89 \%$, and $20.25 \%$, respectively. The hysteresis of the devices was evaluated based on the $J-V$ curves collected by scanning the device from forward bias (FB) to the short circuit (SC) named as $\mathrm{F}$ followed by scanning from $\mathrm{SC}$ to $\mathrm{FB}$ named as $\mathrm{R}$ (Figures $7 \mathrm{~d}-\mathrm{f}$ and S9). The data has revealed that the devices based on new HTMs of 2Cz-OMeDPA and 3Cz-OMeDPA-OH exhibited similar hysteretic behavior as compared to spiroOMeTAD.

To realize the performance difference between the HTMs, time-resolved photoluminescence (TRPL) measurements (Figure 7c) based on glass/perovskite/HTMs construction were performed to study the decay to hole injection processes, as well as the decay time was fitted by the bi-exponential model with the fast $\left(\tau_{1}\right)$ and slow $\left(\tau_{2}\right)$ components, which indicated the interfacial transportation and recombination; the average delay time $\left(\tau_{\text {ave }}\right)$ is calculated by $\tau_{\text {ave }}=\frac{\sum A_{\mathrm{i}} \tau_{\mathrm{i}}^{2}}{\sum A_{\mathrm{i}} \tau_{\mathrm{i}}}$, where $A_{\mathrm{i}}$ and $\tau_{\mathrm{i}}$ represent the decay amplitude and components of delay time, respectively. For the interfacial transportation, the fast $\left(\tau_{1}\right)$ components were considered. As expected, a significant quenching is visible in the first 50 ns for the most efficient HTMs. The derived time constants of 21.3 and 43.6 ns were retrieved for 2Cz-OMeDPA and 3Cz-OMeDPA-OH, respectively, and a somewhat faster process with $\tau=16.8$ ns was obtained for the spiro-OMeTAD/perovskite interface (Table $\mathrm{S} 1)$. On the contrary, a long-living component was observed for the least efficient compounds. These results have indicated that all of the HTMs can assist the hole transportation and 2Cz-OMeDPA is the best among HTMs for the hole 
(a)

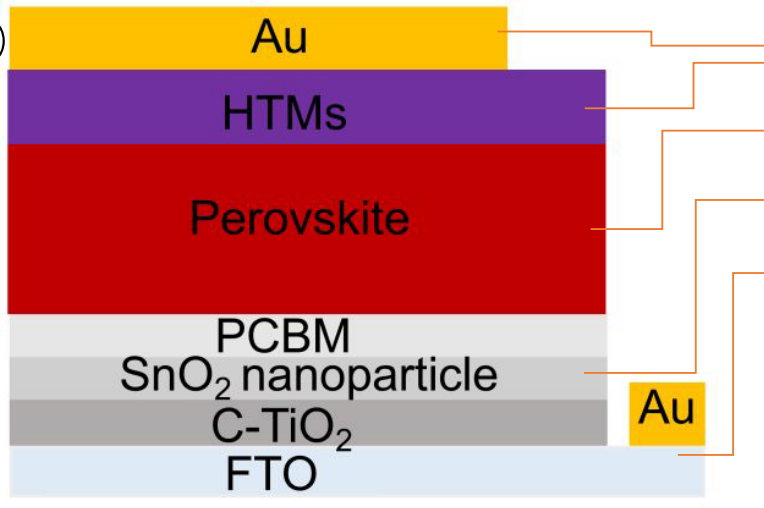

(b)

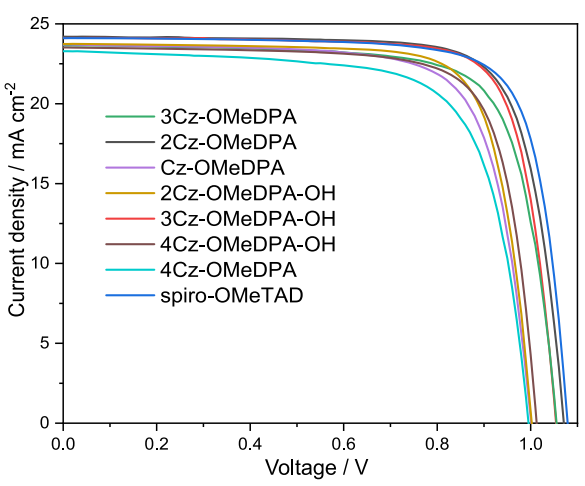

(e)

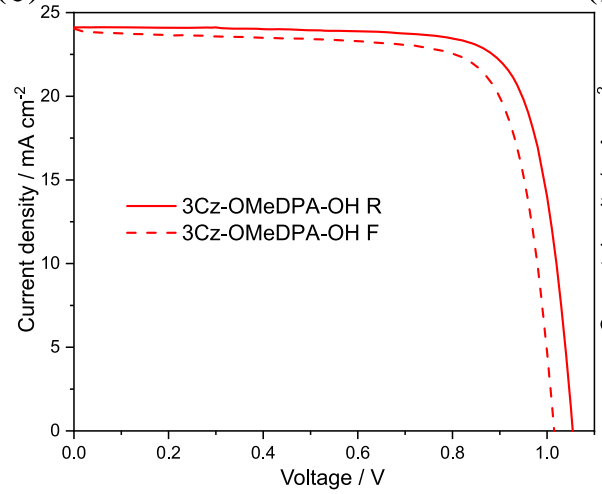

(c)

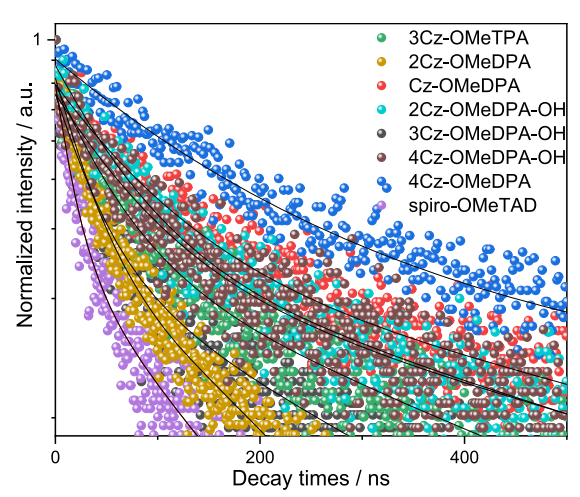

(f)

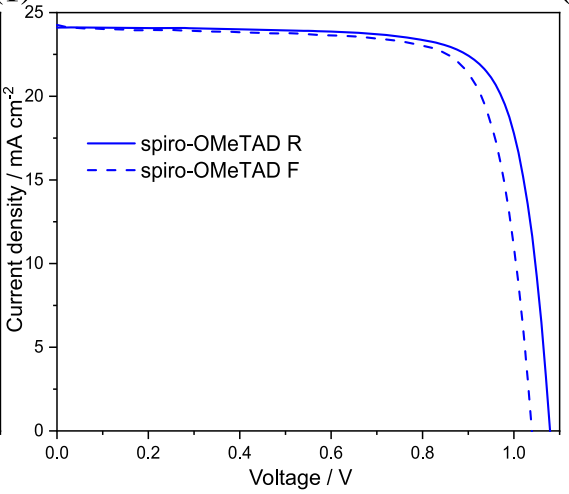

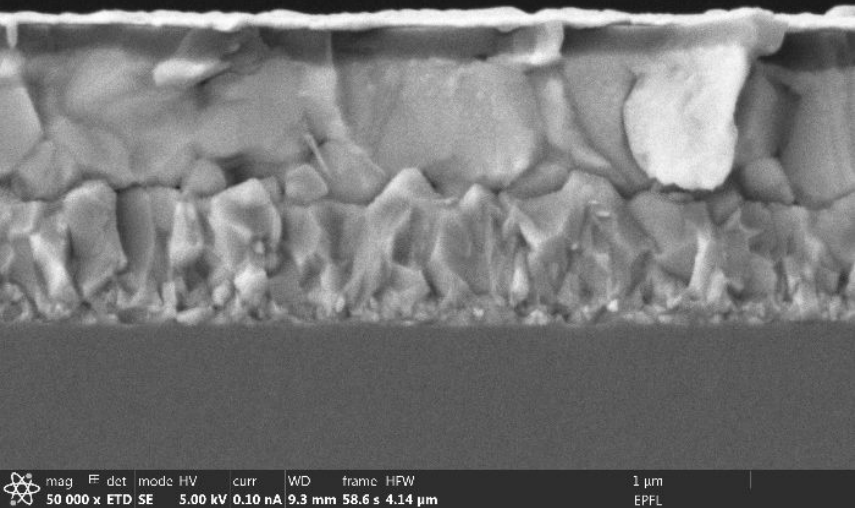

(d)

Figure 7. (a) Illustration of the devices constructed from $\mathrm{FTO} / \mathrm{C}-\mathrm{TiO}_{2} / \mathrm{SnO}_{2} / \mathrm{PCBM} /$ perovskite $/ \mathrm{HTM} / \mathrm{Au}$, along with the corresponding crosssectional SEM image; (b) champion $J-V$ curves of various HTMs based on PSC; (c) TRPL of various HTMs in the construction of glass/ perovskite/HTM; reverse and forward scan of $J-V$ curves based on (d) 2Cz-OMeDPA, (e) 3Cz-OMeDPA-OH, and (f) spiro-OMeTAD; and (g) stability of devices based on spiro-OMeTAD, 3Cz-OMeDPA-OH, and 2Cz-OMeDPA (the humidity is lower than $10 \%, \mathrm{~N}_{2}$-filled box).

collection, which is just a little less for the hole transportation efficiency than spiro-OMeTAD. The results may be the reason for the slightly lower PCE of 2Cz-OMeDPA compared with that of spiro-OMeTAD.

As shown in Figure $7 \mathrm{~g}$, the stability of the unencapsulated devices containing the best performing HTMs was measured under 1 sun illumination while stored under a $\mathrm{N}_{2}$ atmosphere. Devices containing 2Cz-OMeDPA are the most stable, and their stability was slightly better than that of the devices containing 3Cz-OMeDPA-OH and spiro-OMeTAD.

\section{CONCLUSIONS}

To conclude, the synthesis and a systematic study of the branched molecules bearing a different number of 3,6-bis $\left(4,4^{\prime}\right.$ - dimethoxydiphenylamino)carbazole (Cz-OMeDPA) in the periphery linked by aliphatic chains as hole-transporting materials for PSCs are reported. The influence of the different number of $\mathrm{Cz}$-OMeDPA fragments has been revealed through the optical, electrochemical, photophysical, and photovoltaic measurements. Notably, the molecular engineering of $\mathrm{Cz}$ OMeDPA arms resulted in the charge drift mobility of $\mu_{0}=3.1$ $\times 10^{-5} \mathrm{~cm}^{2} \mathrm{~V}^{-1} \mathrm{~s}^{-1}$, which is comparable to that of the reference standard spiro-OMeTAD $\left(4.1 \times 10^{-5} \mathrm{~cm}^{2} \mathrm{~V}^{-1} \mathrm{~s}^{-1}\right)$ under identical conditions. Most importantly, PSCs employing 2Cz-OMeDPA bearing two carbazole chromophores showed a performance of over $20 \%$, which is the best result among the series being on par with spiro-OMeTAD, and demonstrated the enhanced device stability. 
Table 2. Photovoltaic Parameters of Reverse (R) and Forward (F) Scans Obtained from the Champion Devices Based on Various HTMs

\begin{tabular}{lcccc}
\multicolumn{1}{c}{ HTMs } & $J_{\text {sc }}\left(\mathrm{mA} \mathrm{cm}^{-2}\right)$ & $V_{\text {oc }}(\mathrm{V})$ & FF $(\%)$ & PCE (\%) \\
Cz-OMeDPA R & 23.62 & 1.009 & 74.3 & 17.77 \\
Cz-OMeDPA F & 23.35 & 0.985 & 72.6 & 16.73 \\
2Cz-OMeDPA R & 24.15 & 1.071 & 77.4 & 20.06 \\
2Cz-OMeDPA F & 24.16 & 1.021 & 76.6 & 18.95 \\
2Cz-OMeDPA-OH R & 23.7 & 1.001 & 77.2 & 18.33 \\
2Cz-OMeDPA-OH F & 23.24 & 0.971 & 73.4 & 16.60 \\
3Cz-OMeDPA R & 23.59 & 1.054 & 75.1 & 18.72 \\
3Cz-OMeDPA F & 23.26 & 1.004 & 74.2 & 17.38 \\
3Cz-OMeDPA-OH R & 24.05 & 1.054 & 78.3 & 19.89 \\
3Cz-OMeDPA-OH F & 24.07 & 1.015 & 75.9 & 18.53 \\
4Cz-OMeDPA-OH R & 23.51 & 1.012 & 76.3 & 18.15 \\
4Cz-OMeDPA-OH F & 23.61 & 0.988 & 76 & 17.78 \\
4Cz-OMeDPA R & 23.36 & 0.993 & 71.1 & 16.55 \\
4Cz-OMeDPA F & 22.16 & 0.946 & 67.5 & 14.19 \\
spiro-OMeTAD R & 24.05 & 1.079 & 77.9 & 20.25 \\
spiro-OMeTAD F & 24.22 & 1.039 & 76.7 & 19.33 \\
\hline
\end{tabular}

\section{METHODS}

Ionization Potential Measurements. The solid-state ionization potential $\left(I_{\mathrm{p}}\right)$ was measured according to the electron photoemission in air $^{42-44}$ by dissolving HTMs in THF and coating layers of $0.5-1$ $\mu \mathrm{m}$ thickness on the Al plate, which was precoated with methyl methacrylate and methacrylic acid copolymer adhesive layers $(\sim 0.5$ $\mu \mathrm{m}$ thick). Samples were illuminated with monochromatic light originating from a quartz monochromator with a deuterium lamp. The power of the incident light beam was $2-5 \times 10^{-8} \mathrm{~W}$. A negative voltage of $-300 \mathrm{~V}$ was supplied to the sample substrate. A counter electrode with a $4.5 \times 15 \mathrm{~mm}^{2}$ slit for illumination was placed at a distance of $8 \mathrm{~mm}$ from the sample surface. For the photocurrent measurement, the counter electrode was connected to the input of the BK2-16 type electrometer working in the open input regime. The strength of the photocurrent in the circuit under illumination was $10^{-15}-10^{-12}$ A. The photocurrent $I$ depends on the incident light photon energy $h \nu$. The $I^{0.5}=f(h \nu)$ dependence was plotted. The dependence of the photocurrent on incident light quanta energy is described by a linear relationship between $I^{0.5}$ and $h \nu$ near the threshold. The linear part of this dependence was extrapolated to the $h \nu$ axis, and the $I_{\mathrm{p}}$ value was determined as the photon energy at the interception point.

Hole-Drift Mobility Measurements. Samples were prepared by spin-coating the HTM solution on the polyester film with a conductive Al layer. The thickness of the spin-coated layer was 5$10 \mu \mathrm{m}$. The hole-drift mobility was measured by XTOF. ${ }^{45,46}$ The electric field was created by positive corona charging. Charge carriers were generated at the layer surface by illumination with pulses of the nitrogen laser (pulse duration, $2 \mathrm{~ns}$; wavelength, $337 \mathrm{~nm}$ ). The layer surface potential decreased up to $1-5 \%$ of initial potential before illumination as a result of pulse illumination. The capacitance probe connected to the wide frequency band electrometer measured the speed of the surface potential decrease $\mathrm{d} U / \mathrm{d} t$. The transit time $t_{\mathrm{t}}$ was determined by the kink on the curve of the $\mathrm{d} U / \mathrm{d} t$ transient on a double logarithmic scale. Drift mobility was calculated according to the formula $\mu=d^{2} / U_{0} t_{t}$, where $d$ is the layer thickness and $U_{0}$ is the surface potential at the moment of illumination.

Thermal Properties. DSC was performed with a Q10 calorimeter (TA Instruments) at a scan rate of $10 \mathrm{~K} \mathrm{~min}^{-1}$ under a nitrogen atmosphere. The glass-transition temperature of each synthesized compound was determined during the second heating scan. TGA was performed with a Q50 TGA (TA Instruments) at a scan rate of $10 \mathrm{~K}$ $\mathrm{min}^{-1}$ under a nitrogen atmosphere.

Device Fabrication. The chemically etched FTO glass (Nippon Sheet Glass) was cleaned with detergent solution, followed by acetone and then ethanol. The $\mathrm{C}-\mathrm{TiO}_{2}$ layer was prepared by spraying TAA solution in ethanol ( $0.2 \mathrm{~mL}$ of TAA in $6 \mathrm{~mL}$ of anhydrous ethanol) at $450{ }^{\circ} \mathrm{C} . \mathrm{SnO}_{2}$ nanoparticles were diluted with deionized water in a ratio of $1: 4$ and coated on the $\mathrm{C}-\mathrm{TiO}_{2}$ substrate at a speed of 3000 $\mathrm{rpm}$ for $20 \mathrm{~s}$ with a ramp-up of $2000 \mathrm{rpm} \mathrm{s}^{-1}$ followed by the final heating at $150{ }^{\circ} \mathrm{C}$ for $10 \mathrm{~min}$. A $10 \mathrm{mg} / \mathrm{mL}$ concentration solution of PCBM in chlorobenzene was prepared and was spin-coated on the $\mathrm{SnO}_{2}$ layer at a speed of $3000 \mathrm{rpm}$ for $20 \mathrm{~s}$ with a ramp-up of 2000 $\mathrm{rpm} \mathrm{s}^{-1}$ followed by the final heating at $100{ }^{\circ} \mathrm{C}$ for $10 \mathrm{~min}$. Afterward, perovskite solutions (the ratio of $\mathrm{PbI}_{2}, \mathrm{MAI}, \mathrm{FAI}$, and $\mathrm{PbBr}_{2}$ was 1:0.16:0.84:0.11, and $1.38 \mathrm{mmol} / \mathrm{mL} \mathrm{PbI}_{2}$ solution and $0.305 \mathrm{mmol} /$ $\mathrm{mL} \mathrm{MACl}$ solution were added to the perovskite solution; the solvent was prepared by mixing DMSO and DMF in a ratio of 1:4) were successively spin-coated on the substrates at $1000 \mathrm{rpm}$ for $10 \mathrm{~s}$ and $5000 \mathrm{rpm}$ for $30 \mathrm{~s}$, respectively. Chlorobenzene $(200 \mu \mathrm{L})$ was added dropwise for $10 \mathrm{~s}$ at $5000 \mathrm{rpm}$. Perovskite films were annealed at 150 ${ }^{\circ} \mathrm{C}$ for $10 \mathrm{~min}$. The control HTM solution was prepared by dissolving $75 \mathrm{mg}$ of spiro-OMeTAD (Merck) and additives in $1 \mathrm{~mL}$ of chlorobenzene. For each sample solution of the synthesized HTMs, $50 \mathrm{mg}$ of the compound was dissolved in $1 \mathrm{~mL}$ of chlorobenzene. Libis(trifluoromethanesulfonyl)imide $(18 \mu \mathrm{L})$ from the stock solution (520 mg in $1 \mathrm{~mL}$ of acetonitrile), $13 \mu \mathrm{L}$ of FK209 [tris (2-(1Hpyrazol-1-yl)-4-tert-butylpyridine)-cobalt(III) tris(bis (trifluoromethylsulfonyl)imide) (375 mg in $1 \mathrm{~mL}$ of acetonitrile)], and $30 \mu \mathrm{L}$ of 4-tert-butylpyridine were added as additives. The HTM layer was formed by spin-coating the solution at $4000 \mathrm{rpm}$ for $20 \mathrm{~s}$. As the final step, the $70 \mathrm{~nm}$ thick Au electrode was deposited by thermal evaporation. All preparative work to deposit PCBM, perovskite, and HTMs was performed inside the glove box under nitrogen to minimize the influence of moisture and oxygen.

Device Characterization. The SEM of the film morphology was investigated by using a high-resolution SEM (Merlin, Zeiss) equipped with a GEMINI II column and a Schottky Field Emission gun. Images were acquired with an in-lens secondary electron detector. For the PL lifetime measurements, samples were excited with a $408 \mathrm{~nm}$ pulsed laser (MDL 300, PicoQuant) with a pulse energy density of $40 \mu \mathrm{m}$ $\mathrm{cm}^{-2}$. Current-voltage characteristics were recorded by applying an external potential bias to the cell while recording the generated photocurrent with a digital source meter (Keithley Model 2400). The light source was a $450 \mathrm{~W}$ xenon lamp (Oriel) equipped with a Schott K113 Tempax sunlight filter (Praezisions Glas \& Optik GmbH) to match the emission spectrum of the lamp to the AM1.5G standard. Before each measurement, the exact light intensity was determined using a calibrated Si reference diode equipped with an infrared cutoff filter (KG-3, Schott). The cells were masked with an active area of $0.09 \mathrm{~cm}^{2}$ to fix the active area and reduce the influence of the scattered light for the small device. All measurements were carried out at room temperature in air.

\section{ASSOCIATED CONTENT}

\section{Supporting Information}

The Supporting Information is available free of charge at https://pubs.acs.org/doi/10.1021/acs.chemmater.1c02114.

General procedures, synthetic methods, additional figures, and tables (DSC, UV-PL, hysteresis, fitting parameters, etc.) (PDF)

\section{AUTHOR INFORMATION}

\section{Corresponding Authors}

Vytautas Getautis - Department of Organic Chemistry, Kaunas University of Technology, Kaunas 50254, Lithuania; ○ orcid.org/0000-0001-7695-4677;

Email: vytautas.getautis@ktu.lt

Mohammad Khaja Nazeeruddin - Group for Molecular Engineering of Functional Material, Institute of Chemical Sciences and Engineering, Ecole Polytechnique Fédérale de 
Lausanne, CH-1951 Sion, Switzerland; 이이.org/00000001-5955-4786; Email: mdkhaja.nazeeruddin@epfl.ch

\section{Authors}

Povilas Luizys - Department of Organic Chemistry, Kaunas University of Technology, Kaunas 50254, Lithuania

Jianxing Xia - Group for Molecular Engineering of Functional Material, Institute of Chemical Sciences and Engineering, Ecole Polytechnique Fédérale de Lausanne, CH-1951 Sion, Switzerland

Maryte Daskeviciene - Department of Organic Chemistry, Kaunas University of Technology, Kaunas 50254, Lithuania

Kristina Kantminiene - Department of Physical and Inorganic Chemistry, Kaunas University of Technology, Kaunas 50254, Lithuania

Ernestas Kasparavicius - Department of Organic Chemistry, Kaunas University of Technology, Kaunas 50254, Lithuania

Hiroyuki Kanda - Group for Molecular Engineering of Functional Material, Institute of Chemical Sciences and Engineering, Ecole Polytechnique Fédérale de Lausanne, $\mathrm{CH}$ 1951 Sion, Switzerland; 이이.org/0000-0002-03278775

Yi Zhang - Group for Molecular Engineering of Functional Material, Institute of Chemical Sciences and Engineering, Ecole Polytechnique Fédérale de Lausanne, CH-1951 Sion, Switzerland

Vygintas Jankauskas - Institute of Chemical Physics Vilnius University, Vilnius 10257, Lithuania

Kasparas Rakstys - Department of Organic Chemistry, Kaunas University of Technology, Kaunas 50254, Lithuania

Complete contact information is available at:

https://pubs.acs.org/10.1021/acs.chemmater.1c02114

\section{Author Contributions}

${ }^{\#}$ P.L. and J.X. contributed equally to this work.

\section{Notes}

The authors declare no competing financial interest.

\section{ACKNOWLEDGMENTS}

The authors acknowledge the support of the H2020 program for Solar-ERANET funding of the BOBTANDEM (20192022) and the Swiss National Science Foundation. K.R. acknowledges funding from the Research Council of Lithuania via Grant no. 09.3.3-LMT-K-712-19-0061 and the funding received from the MJJ Foundation. Dr. E. Kamarauskas is acknowledged for ionization potential measurements.

\section{REFERENCES}

(1) Rong, Y.; Hu, Y.; Mei, A.; Tan, H.; Saidaminov, M. I.; Il, S. S.; McGehee, M. D.; Sargent, E. H.; Han, H. Challenges for Commercializing Perovskite Solar Cells. Science 2018, 361, No. eaat8235.

(2) Kojima, A.; Teshima, K.; Shirai, Y.; Miyasaka, T. Organometal Halide Perovskites as Visible-Light Sensitizers for Photovoltaic Cells. J. Am. Chem. Soc. 2009, 131, 6050-6051.

(3) Best Research-Cell Efficiency Chart I Photovoltaic Research I NREL. 2021.

(4) Green, M. A.; Ho-Baillie, A.; Snaith, H. J. The Emergence of Perovskite Solar Cells. Nat. Photonics 2014, 8, 506-514.

(5) Park, N.-G. Perovskite Solar Cells: An Emerging Photovoltaic Technology. Mater. Today 2015, 18, 65-72.

(6) Vaitukaityte, D.; Wang, Z.; Malinauskas, T.; Magomedov, A.; Bubniene, G.; Jankauskas, V.; Getautis, V.; Snaith, H. J. Efficient and
Stable Perovskite Solar Cells Using Low-Cost Aniline-Based Enamine Hole-Transporting Materials. Adv. Mater. 2018, 30, 1-7.

(7) Yu, Z.; Sun, L. Recent Progress on Hole-Transporting Materials for Emerging Organometal Halide Perovskite Solar Cells. Adv. Energy Mater. 2015, 5, 1500213.

(8) Teh, C. H.; Daik, R.; Lim, E. L.; Yap, C. C.; Ibrahim, M. A.; Ludin, N. A.; Sopian, K.; Mat Teridi, M. A. A. Review of Organic Small Molecule-Based Hole-Transporting Materials for MesoStructured Organic-Inorganic Perovskite Solar Cells. J. Mater. Chem. A 2016, 4, 15788-15822.

(9) Ameen, S.; Rub, M. A.; Kosa, S. A.; Alamry, K. A.; Akhtar, M. S.; Shin, H. S.; Seo, H. K.; Asiri, A. M.; Nazeeruddin, M. K. Perovskite Solar Cells: Influence of Hole Transporting Materials on Power Conversion Efficiency. ChemSusChem 2016, 9, 10-27.

(10) Calió, L.; Kazim, S.; Grätzel, M.; Ahmad, S. Hole-Transport Materials for Perovskite Solar Cells. Angew. Chem., Int. Ed. 2016, 55, $14522-14545$.

(11) Wang, Y.-K.; Jiang, Z.-Q.; Liao, L.-S. New Advances in Small Molecule Hole-Transporting Materials for Perovskite Solar Cells. Chin. Chem. Lett. 2016, 27, 1293-1303.

(12) Urieta-Mora, J.; García-Benito, I.; Molina-Ontoria, A.; Martín, N. Hole Transporting Materials for Perovskite Solar Cells: A Chemical Approach. Chem. Soc. Rev. 2018, 47, 8541-8571.

(13) Zhou, W.; Wen, Z.; Gao, P. Less Is More: Dopant-Free Hole Transporting Materials for High-Efficiency Perovskite Solar Cells. Adv. Energy Mater. 2018, 8, 1702512.

(14) Rakstys, K.; Igci, C.; Nazeeruddin, M. K. Efficiency vs. Stability: Dopant-Free Hole Transporting Materials towards Stabilized Perovskite Solar Cells. Chem. Sci. 2019, 10, 6748-6769.

(15) Sheibani, E.; Yang, L.; Zhang, J. Recent Advances in Organic Hole Transporting Materials for Perovskite Solar Cells. Sol. RRL 2020, 4, 2000461.

(16) Yin, X.; Song, Z.; Li, Z.; Tang, W. Toward Ideal Hole Transport Materials: A Review on Recent Progress in Dopant-Free Hole Transport Materials for Fabricating Efficient and Stable Perovskite Solar Cells. Energy Environ. Sci. 2020, 13, 4057-4086.

(17) Kato, S.; Noguchi, H.; Kobayashi, A.; Yoshihara, T.; Tobita, S.; Nakamura, Y. Bicarbazoles: Systematic Structure-Property Investigations on a Series of Conjugated Carbazole Dimers. J. Org. Chem 2012, 77, 9120-9133.

(18) Prachumrak, N.; Pojanasopa, S.; Namuangruk, S.; Kaewin, T.; Jungsuttiwong, S.; Sudyoadsuk, T.; Promarak, V. Novel Bis[5(Fluoren-2-Yl)Thiophen-2-Yl]Benzothiadiazole End-Capped with Carbazole Dendrons as Highly Efficient Solution-Processed Nondoped Red Emitters for Organic Light-Emitting Diodes. ACS Appl. Mater. Interfaces 2013, 5, 8694-8703.

(19) Wex, B.; Kaafarani, B. R. Perspective on Carbazole-Based Organic Compounds as Emitters and Hosts in TADF Applications. J. Mater. Chem. C 2017, 5, 8622-8653.

(20) Ledwon, P. Recent Advances of Donor-Acceptor Type Carbazole-Based Molecules for Light Emitting Applications. Org. Electron. 2019, 75, 105422.

(21) Lai, H.; Hong, J.; Liu, P.; Yuan, C.; Li, Y.; Fang, Q. MultiCarbazole Derivatives: New Dyes for Highly Efficient Dye-Sensitized Solar Cells. RSC Adv. 2012, 2, 2427.

(22) El-Sherbiny, D.; Cheema, H.; El-Essawy, F.; Abdel-Megied, A.; El-Shafei, A. Synthesis and Characterization of Novel CarbazoleBased Terpyridyl Photosensitizers for Dye-Sensitized Solar Cells (DSSCs). Dyes Pigm. 2015, 115, 81-87.

(23) An, J.; Yang, X.; Cai, B.; Zhang, L.; Yang, K.; Yu, Z.; Wang, X.; Hagfeldt, A.; Sun, L. Fine-Tuning by Triple Bond of Carbazole Derivative Dyes to Obtain High Efficiency for Dye-Sensitized Solar Cells with Copper Electrolyte. ACS Appl. Mater. Interfaces 2020, 12, 46397-46405.

(24) Daskeviciene, M.; Paek, S.; Wang, Z.; Malinauskas, T.; Jokubauskaite, G.; Rakstys, K.; Cho, K. T.; Magomedov, A.; Jankauskas, V.; Ahmad, S.; et al. Carbazole-Based Enamine: LowCost and Efficient Hole Transporting Material for Perovskite Solar Cells. Nano Energy 2017, 32, 551-557. 
(25) Li, M.; Wang, Z.; Liang, M.; Liu, L.; Wang, X.; Sun, Z.; Xue, S. Low-Cost Carbazole-Based Hole-Transporting Materials for Perovskite Solar Cells: Influence of S,N-Heterocycle. J. Phys. Chem. C 2018, $122,24014-24024$.

(26) Berton, N.; Nakar, R.; Schmaltz, B. DMPA-Containing Carbazole-Based Hole Transporting Materials for Perovskite Solar Cells: Recent Advances and Perspectives. Synth. Met. 2019, 252, 91106.

(27) Daskeviciene, M.; Paek, S.; Magomedov, A.; Cho, K. T.; Saliba, M.; Kizeleviciute, A.; Malinauskas, T.; Gruodis, A.; Jankauskas, V.; Kamarauskas, E.; et al. Molecular Engineering of Enamine-Based Small Organic Compounds as Hole-Transporting Materials for Perovskite Solar Cells. J. Mater. Chem. C 2019, 7, 2717-2724.

(28) Gao, L.; Schloemer, T. H.; Zhang, F.; Chen, X.; Xiao, C.; Zhu, K.; Sellinger, A. Carbazole-Based Hole-Transport Materials for HighEfficiency and Stable Perovskite Solar Cells. ACS Appl. Energy Mater. 2020, 3, 4492-4498.

(29) Rakstys, K.; Paek, S.; Drevilkauskaite, A.; Kanda, H.; Daskeviciute, S.; Shibayama, N.; Daskeviciene, M.; Gruodis, A.; Kamarauskas, E.; Jankauskas, V.; et al. Carbazole-Terminated Isomeric Hole-Transporting Materials for Perovskite Solar Cells. ACS Appl. Mater. Interfaces 2020, 12, 19710-19717.

(30) Xu, B.; Sheibani, E.; Liu, P.; Zhang, J.; Tian, H.; Vlachopoulos, N.; Boschloo, G.; Kloo, L.; Hagfeldt, A.; Sun, L. Carbazole-Based Hole-Transport Materials for Efficient Solid-State Dye-Sensitized Solar Cells and Perovskite Solar Cells. Adv. Mater. 2014, 26, 66296634.

(31) Li, D.; Shao, J.-Y.; Li, Y.; Li, Y.; Deng, L.-Y.; Zhong, Y.-W.; Meng, Q. New Hole Transporting Materials for Planar Perovskite Solar Cells. Chem. Commun. 2018, 54, 1651-1654.

(32) Zhu, L.; Shan, Y.; Wang, R.; Liu, D.; Zhong, C.; Song, Q.; Wu, F. High-Efficiency Perovskite Solar Cells Based on New TPE Compounds as Hole Transport Materials: The Role of 2,7- and 3,6Substituted Carbazole Derivatives. Chem. - Eur. J. 2017, 23, 43734379.

(33) Gratia, P.; Magomedov, A.; Malinauskas, T.; Daskeviciene, M.; Abate, A.; Ahmad, S.; Grätzel, M.; Getautis, V.; Nazeeruddin, M. K. A Methoxydiphenylamine-Substituted Carbazole Twin Derivative: An Efficient Hole-Transporting Material for Perovskite Solar Cells. Angew. Chem., Int. Ed. 2015, 54, 11409-11413.

(34) Magomedov, A.; Paek, S.; Gratia, P.; Kasparavicius, E.; Daskeviciene, M.; Kamarauskas, E.; Gruodis, A.; Jankauskas, V.; Kantminiene, K.; Cho, K. T.; et al. Diphenylamine-Substituted Carbazole-Based Hole Transporting Materials for Perovskite Solar Cells: Influence of Isomeric Derivatives. Adv. Funct. Mater. 2018, 28, 1704351.

(35) Benhattab, S.; Nakar, R.; Rodriguez Acosta, J. W.; Berton, N.; Faure-Vincent, J.; Bouclé, J.; Tran Van, F.; Schmaltz, B. CarbazoleBased Twin Molecules as Hole-Transporting Materials in DyeSensitized Solar Cells. Dyes Pigm. 2018, 151, 238-244.

(36) Tomkute-Luksiene, D.; Daskeviciene, M.; Malinauskas, T.; Jankauskas, V.; Degutyte, R.; Send, R.; Pschirer, N. G.; Wonneberger, H.; Bruder, I.; Getautis, V. Molecular Engineering of the HoleTransporting Material Spiro-OMeTAD via Manipulation of Alkyl Groups. RSC Adv. 2016, 6, 60587-60594.

(37) Tomkute-Luksiene, D.; Malinauskas, T.; Daskeviciene, M.; Gaidelis, V.; Maldzius, R.; Sidaravicius, J.; Getautis, V. Synthesis of the Hole-Transporting Molecular Glasses Possessing Pendant 3,6Dibromocarbazolyl Moieties. Synth. Met. 2011, 161, 1177-1185.

(38) Malinauskas, T.; Tomkute-Luksiene, D.; Sens, R.; Daskeviciene, M.; Send, R.; Wonneberger, H.; Jankauskas, V.; Bruder, I.; Getautis, V. Enhancing Thermal Stability and Lifetime of Solid-State DyeSensitized Solar Cells via Molecular Engineering of the HoleTransporting Material Spiro-OMeTAD. ACS Appl. Mater. Interfaces 2015, 7, 11107-11116

(39) Borsenberger, P. M.; Pautmeier, L.; Bässler, H. Charge Transport in Disordered Molecular Solids. J. Chem. Phys. 1991, 94, $5447-5454$
(40) Yu, W.; Yang, Q.; Zhang, J.; Tu, D.; Wang, X.; Liu, X.; Li, G.; Guo, X.; Li, C. Simple Is Best: A p-Phenylene Bridging Methoxydiphenylamine-Substituted Carbazole Hole Transporter for High-Performance Perovskite Solar Cells. ACS Appl. Mater. Interfaces 2019, 11, 30065-30071.

(41) De Mello, J. C.; Wittmann, H. F.; Friend, R. H. An Improved Experimental Determination of External Photoluminescence Quantum Efficiency. Adv. Mater. 1997, 9, 230-232.

(42) Cardona, M.; Ley, L. Photoemission in Solids I - General Principles, Springer: Berlin, Heidelberg, 1978; Vol. 26. DOI: 10.1007/ 3-540-08685-4

(43) Miyamoto, E.; Yamaguchi, Y.; Yokayama, M. Ionization potential of organic pigment thin film by atmospheric photoelectron analysis. J. Xerography 1989, 28, 364-370.

(44) Kirkus, M.; Tsai, M. H.; Grazulevicius, J. V.; Wu, C. C.; Chi, L. C.; Wong, K. T. New Indole-Carbazole Hybrids as Glass-Forming High-Triplet-Energy Materials. Synth. Met. 2009, 159, 729-734.

(45) Vaezi-Nejad, S. M. Xerographic Time of Flight Experiment for the Determination of Drift Mobility in High Resistivity Semiconductors. Int. J. Electron. 1987, 62, 361-384.

(46) Chan, A. Y. C.; Juhasz, C. Xerographic-Mode Transient Charge Technique for Probing Drift Mobility in High-Resistivity Materials. Int. J. Electron. 1987, 62, 625-632. 